
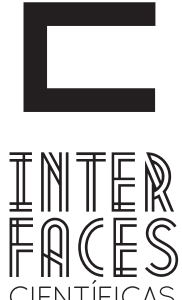

CIENTÍFICAS

HUMANASE SOCIAIS

\title{
ÂNCORAS DE CARREIRA - UM ESTUDO DE CAMPO COM OS ALUNOS DE ENGENHARIA
}

\author{
gor Polezi Munhoz ${ }^{1}$ \\ Jorge Luiz Knupp ${ }^{3}$ \\ Alessandra Cristina Santos Akkari
}

Neusa Maria Bastos Fernandes dos Santos ${ }^{2}$ Roberto Fernandes dos Santos ${ }^{4}$ Luís Henrique Lopes ${ }^{6}$

\section{RESUMO}

A gestão de carreiras pode ser vista como uma forma interligada a outras dimensões, determinadas a partir de valores, competências e necessidades individuais. Este artigo tem dois principais objetivos. 0 primeiro deles é identificar as principais âncoras de carreira e inclinações profissionais com um grupo de estudantes da área de Engenharia, pertencentes em sua maioria à geração Y. O segundo é verificar estatisticamente se há associação entre os oito diferentes tipos de âncoras de carreira e o perfil deste alunado considerando o gênero, a idade e a formação acadêmica básica. 0 referencial teórico foi suportado pela abordagem de âncoras de carreira de Schein (1993). O levantamento bibliográfico buscou referenciar dissertações, artigos, periódicos e textos integrais em diversas fontes, em bancos de dados nacionais e internacionais. Foram sujeitos do estudo 252 alunos do curso de Engenharia de Gestão da Universidade Federal do ABC (UFABC), sendo que para a composição da amostra utilizou o critério de acessibilidade. A pesquisa de campo foi realizada com a aplicação do inventário de avaliação das inclinações de carreira, constituído de 40 afirmações e utilizando-se uma escala Likert com 6 pontos, para identificação dos oito tipos de âncoras de carreira. O tratamento dos dados foi feito com auxilio do pacote estatístico SPSS (versão 13.0) e os resultados organizados em análise descritiva e análise inferencial. 0 estudo apontou que as duas principais âncoras de carreira para o grupo pesquisado foram Estilo de Vida (18\%) e Segurança e Estabilidade (16\%) e também revelou que a âncora com menor frequência é a de Dedicação a uma Causa, com frequência de apenas 5\%. Os testes estatísticos para um nível de significância de 5\% determinaram 
que não há associação direta entre a escolha especifica de uma âncora de carreira e outras variáveis de referência como gênero, idade e formação educacional. A necessidade de ampliar o plano amostral e investir em pesquisas comparadas sobre âncoras de carreira e valores pessoais é relevante, pois podem fornecer subsídios para um adequado enfrentamento dos problemas e desafios no processo de gestão de carreiras.

\section{PALAVRAS-CHAVE}

\section{Carreira. Âncoras. Competências, Geração Y.}

\section{ABSTRACT}

The career management can be interconnected to other dimensions, determined from values, skills and individual needs. This article has two main objectives. The first is to identify the main anchors of career and professional inclinations with a group of students of Engineering, belong ing mostly to the $Y$ generation. The second is statistically verify whether there is an association between the eight different types of career anchors and profile of this student body considering gender, age and basic academic education. The theoretical approach was supported by the career anchors of Schein(1993). The bibliographic reference sought dissertations, articles, periodicals and full texts from various sources, in national and international databases. Have been the subject of study 252 students of Engineering Management from the Federal University of $A B C$ (UFABC) and the composition of the sample used the criteria of accessibility. The field research was conducted with the application of assessment inventory slopes career, consists of 40 statements and using a Likert scale with 6 points, for identification of

\section{RESUMEN}

La gestión de la carrera puede ser visto como un interconectado a otras dimensiones, determinadas a partir de los valores, habilidades y necesidades forma individual. Este artículo tiene dos objetivos principales. La primera es identificar las principales anclas de carrera y profesionales inclinaciones con un grupo de estudiantes de ingeniería, que pertenece en su mayoría a la generación Y. La segunda es estadísticamente verificar si existe una asociación entre los ocho diferentes tipos de the eight types of anchors career. The data analysis was done with the aid of the statistical package SPSS (version 13.0) and the results organized in descriptive analysis and inferential analysis. The study found that the two main anchors career to the research group was Lifestyles (18\%) and Security and Stability (16\%) and also revealed that the anchor Dedication to a Cause is less frequently, with only $5 \%$. For statistical significance level of $5 \%$, tests determined that there is no direct association between the specific choice of a career anchor and other reference variables such as gender, age and educational background. The need to expand the sampling plan and invest in comparative research on career anchors and personal values is relevant, because it can provide information for an adequate face problems and challenges in career management process.

\section{KEYWORDS}

Career. Anchors. Skills. Y Generation. anclajes de carrera y perfil de este alumnado teniendo en cuenta el género, la edad y la educación académica básica. El marco teórico principal fue apoyado por el enfoque de los anclajes de carrera de Schein (1993). La referencia bibliográfica buscó tesinas, artículos, revistas y textos completos de diversas fuentes, los bancos en las bases de datos nacionales e internacionales. Han sido objeto de estudio 252 estudiantes de la Ingeniería de Gestión de la Universidad Federal del ABC (UFABC), 
la composición de la muestra utilizaron los criterios de accesibilidad (Vergara, 2007). La investigación de campo se llevó a cabo con la aplicación de las laderas de inventario evaluación de carrera, de acuerdo con Schein (1993). El cuestionario consta de 40 créditos y mediante una escala Likert de 6 puntos, para identificar ocho tipos de anclajes de carrera. El análisis de datos se realizó con la ayuda del paquete estadístico SPSS (versión 13.0) y los resultados organizados en análisis descriptivo y el análisis de inferencia. El estudio encontró que las dos anclas principales carrera con el grupo de investigación fue Estilos de Vida (18\%) y de Seguridad y Estabilidad (16\%). La investigación reveló que el ancla es menos frecuente dedicación a una causa a menu-

\section{INTRODUÇ̃̃̃O}

O conceito de carreira foi ganhando outros elementos, além do sentido meramente do trabalho que the era atribuído no início (MCDANIELS; GYSBERS, 1992).

Na língua inglesa, a palavra carreira correspondia originalmente à estrada para carruagens; e a partir do século XIX, foi utilizada no âmbito do trabalho, passando a designar "um canal para as atividades econômicas de alguém durante a vida inteira” (SENNETT, 2006). Assim pode-se definir carreira como a sequência de experiências relacionadas ao trabalho vivenciadas pelas pessoas ao longo do tempo (ARTHUR; KHAPOVA; WILDEROM, 2005).

Uma carreira tradicional é caracterizada pela permanência do trabalhador em uma mesma organização durante toda sua vida, é incompatível com a necessidade de mudança que as organizações precisam ter para enfrentar as turbulências do ambiente atual. Atualmente as carreiras tendem a ser cíclicas, envolvendo períodos alternados de aprendizagem, de domínio do conhecimento e de reaprendizado (HALL; MIRVIS, 1995). do sólo el 5\%. Para el nivel de significación estadística del 5\% determinó que no existe una asociación directa entre la elección específica de un anclaje de carrera y otras variables de referencia tales como el género, la edad y el nivel educativo. La necesidad de ampliar el espacio de muestra de esta investigación e invertir en la investigación comparativa de la orientación, los ejes de carrera y los valores personales es importante, ya que pueden proporcionar apoyo durante la resolución de problemas y desafíos contenidos en el proceso.

\section{PALABRAS CLAVE}

Carrera. Anclajes. Habilidades. Generación

Dessa forma, falar em carreira nos tempos atuais significa vê-la de forma interligada a essas outras dimensões. Para perspectiva de desenvolvimento de carreira, havia a necessidade de se estabelecer uma relação entre desenvolvimento de carreira e desenvolvimento da vida pessoal e familiar. Para entender a carreira das pessoas, seria necessário entender as suas necessidades e características, as quais não estão ligadas apenas à vida no trabalho, mas que são frutos da interação da pessoa com todos os espaços de sua vida (SCHEIN, 1993).

Na década de 1980, grandes empresas passam a alterar sua estratégia de expansão e verticalização, diminuindo número de empregados e começam a usar contratos temporários de trabalho, o que alterou totalmente os planos de carreira tradicionais devido à falta de instabilidade. Com isso o desenvolvimento de carreira deixou de ocorrer somente dentro das organizações, e cada vez mais esses empregados passaram a ser vistos como semiautônomos, profissionais autoadministrados, cuja segurança não está centrada na organização, mas em suas próprias competências. 
Ao considerar diferentes aspectos, tais como necessidades, desejos, ansiedade, capacidades, potencialidades pessoais, as pressões e condicionantes ambientais da empresa, responsabilidades na vida particular, fizeram com que a ideia de desenvolvimento de carreira estivesse diretamente relacionada com o desenvolvimento pessoal.

A concepção do conceito de âncoras de carreira foi uma contribuição da Sloan School of Management do MIT, que é uma combinação das áreas de competência, motivos e valores do indivíduo.

Ambições da vida profissional e a satisfação das necessidades prioritárias de um indivíduo são levadas em consideração para identificar sua inclinação profissional. Essas são estimuladas por sentimentos e necessidades que se estabelecem a partir do resultado do acúmulo de experiências, componentes essenciais dos quais a pessoa não abre mão, até mesmo em situações de tomadas de decisão.

O estudo de gestão de carreiras é tradicionalmente direcionado para a área de Administração e afins, porém não foram encontradas pesquisas realizadas na área de Engenharia. Esse artigo apresenta dois objetivos principais. 0 primeiro deles é identificar as principais âncoras de carreira e inclinações profissionais em um grupo de estudantes da área de Engenharia da Universidade Federal do $A B C$ (UFABC), pertencentes em sua maioria à geração $Y$. O segundo objetivo é verificar estatisticamente se há associação entre os oito diferentes tipos de âncoras de carreira e o perfil deste alunado considerando o gênero, a idade e a formação acadêmica básica.

Duas questões centrais de pesquisa foram formuladas, quer sejam: 1) Em quais inclinações profissionais os estudantes de Engenharia estão identificados? 2) Quais os fatores externos que influenciam na determinação das ancoras de carreira?
As âncoras de carreira são determinadas a partir de valores, competências, e necessidades das quais o indivíduo considera importante, fatores essenciais dos quais não abriria mão em sua carreira profissional. A determinação de sua inclinação profissional é de extrema utilidade e facilita a tomada de decisões futuras.

Há necessidade de estudos e pesquisas sobre trajetórias, transições e decisões de carreira, segundo as percepções dos próprios indivíduos, o que pode, inclusive, revelar como reagem diante de tão contraditórias tendências do mercado de trabalho.

\section{QUADRO TEÓRICO}

Neste tópico são apresentados os conceitos de carreira, a evolução destes conceitos, a definição de competências, o significado das âncoras de carreira de Schein (1993) e o conceito de Geração Y.

\subsection{CARREIRA}

Diferentes conotações foram atribuídas à palavra carreira ao longo da História. Na língua inglesa, a palavra carreira correspondia originalmente à estrada para carruagens; a partir do século XIX, com a Revolução Industrial usa-se a aplicação do termo ao trabalho, podendo ser descrita como a sequência de experiências relacionadas ao trabaIho vivenciadas pelas pessoas ao longo do tempo (ARTHUR; KHAPOVA; WILDEROM, 2005). Uma carreira tradicional passou a designar um canal de atividades econômicas ao longo da vida do indivíduo. (SENNET, 2006).

Nessa abordagem tradicional, destacam-se três características limitantes do conceito de carreira: expectativa de progressão vertical hierárquica de uma organização, caracterizadas pelas promoções para cargos superiores que geravam maiores salários e status; associação de carreiras a profissão, somen- 
te médicos, advogados, militares teriam carreiras; e pressuposição de estabilidade, em que o empregado exerce as mesmas atividades relacionadas à sua profissão até sua aposentadoria (MARTINS, 2001).

A carreira proteana é um conceito que ultrapassa as limitações da abordagem tradicional, na qual a carreira passa a ser compreendida como uma série de aprendizados pessoais, relacionados ao trabalho ao longo da vida (HALL, 1996). 0 termo é derivado do Deus Proteu, da mitologia grega, conhecido por seus poderes metamórficos. Dessa maneira o conceito de carreira proteana é um processo em que a pessoa e não a organização gerencia sua própria trajetória proffissional, e pode ser redirecionada, de tempos em tempos, para atender às necessidades da pessoa (HALL, 1996).

0 profissional proteano consegue se ajustar às demandas do ambiente de carreiras, com flexibilidade e investimento em suas habilidades, qualificações e competências, mas sempre tendo consciência de seus objetivos pessoais, sabe definir os atributos de sucesso que espera alcançar, coerentes com seus valores, interesses e aptidões, além de ser capaz de priorizar suas ações de carreira, conciliando com sua vida pessoal (MARTINS, 2001).

A carreira consiste em uma ocupação ou profissão representada por etapas e possivelmente por uma progressão. Ingressar em uma carreira significa avançar no caminho da vida (ROBERT, 1989). Assim, levando em consideração a mesma linha de pensamento de carreira proteana, a trajetória de carreira pode ser entendida como a sequência ou evolução das experiências de trabatho de uma pessoa ao longo do tempo, o que não implica em progresso, sucesso ou fracasso, pois qualquer trabalho remunerado ou não, exercido por um período de tempo, pode vir a constituir uma carreira (ROBBINS, 1998). Esse novo modelo de carreira, ou seja, a proteana cria novos caminhos e diferentes modos de buscar a satisfação pessoal e profissional, já que o sucesso é baseado em critérios pessoais.
Chanlat (1995) relacionou as principais causas do declínio da carreira tradicional: penetração crescente das mulheres no mercado de trabalho; elevação dos graus de instrução; afirmação dos direitos dos indivíduos.

A empregabilidade, também, pode ser considerada um novo alvo profissional (MARTINS, 2001). Com tantos processos de mudanças que assolam as instituições estes podem impactar a condição de estabilidade individual, cada vez mais precária, dentro de uma organização. Este quadro de redução do emprego acaba por demandar maior empregabilidade, e sendo assim se faz necessário estar em constante desenvolvimento profissional, quer seja pelos desafios encontrados no trabalho, quer seja pela necessidade de aprendizado individual contínuo.

A relação empregador-empregado, denominada contrato psicológico, refletia as expectativas mútuas na relação de trabalho. Antigamente, assegurava a estabilidade do vínculo em troca da dedicação do empregado aos objetivos organizacionais. Numa abordagem mais recente, pode-se dividir em duas vertentes: o contrato relacional baseado na expectativa de um relacionamento em longo prazo, mutuamente satisfatório e o contrato transacional focado em trocas utilitárias de curto prazo entre o empregado e a organização (HALL, 1996).

O novo contrato proteano tende a combinar tanto as características relacionais assim como as transacionais. Desta forma, a carreira passa a ter um caráter individual, com trajetória imprevisível e multiforme (proteana), guiada por conceitos e valores pessoais em busca do sucesso psicológico.

\subsection{COMPETÊNCIAS}

As preferências vocacionais e as competências individuais mudam com o tempo e com a experiência do indivíduo, fazendo parte de seu processo de desenvolvimento de carreira. 
As empresas necessitam de profissionais que possuam um perfil generalista com competências técnicas, comportamentais e sociais, flexíveis e proativos para movimentar-se e conduzir seu trabalho, gerindo sua carreira de forma objetiva em um mundo de constante mudança (DUTRA, 2002). Para acompanhar todas as constantes mudanças, as organizações estão, cada vez mais, direcionando seus investimentos em desenvolvimento humano para ações que agreguem valor à empresa e também às pessoas (DUCCI, 1996).

O conceito de competências envolve os saberes ou conhecimentos formais, que podem ser traduzidos em fatos e regras, o saber-fazer, que pertence à esfera dos procedimentos empíricos, como as receitas, os truques de ofício, e que se desenvolvem na prática quotidiana de uma profissão e ocupação; finalmente, o saber-ser, compreendido como saber social ou do senso comum, que mobiliza estratégias e raciocínios complexos, interpretações e visões de mundo (LUZ, 2001).

0 modelo baseado em competências do modelo de qualificação, apesar de considerar que as definições atuais deste novo modelo possuem grande influência dos conceitos relacionados à qualificação (ZARIFIAN, 2001).

Alcançar uma condição de alto desempenho pessoal e profissional nesse cenário é o resultado de um processo de conhecer a si mesmo, seu potencial, competências e estar consciente de como é percebido e usar todos esses elementos como sustentáculo para o desenvolvimento pessoal e profissional (DUTRA, 2002).

\section{3 ÂNCORAS DE CARREIRA}

Os conceitos atuais sobre carreira foram estudados por um grupo de pesquisadores do MIT, a partir de um estudo realizado com 44 profissionais que foram entrevistados por Edgar Schein, 10 a 12 anos após a conclusão da graduação. Schein analisou os principais eventos ocorridos nas carreiras dos profissionais. Essas entrevistas enfatizavam a história da vida profissional de cada pessoa e as razões de suas escolhas. O conjunto desses trabalhos tem grande importância na concepção atual de carreira.

0 profissional se torna responsável pela autopercepção e pelo compartilhamento de sua inclinação profissional com pessoas que tenham influência sobre sua carreira, a fim de que se possam ampliar as chances de compatibilização de suas necessidades individuais com as necessidades organizacionais (SHEIN, 1993).

Assim foram classificadas as âncoras de carreira em oito categorias, apesar de a maioria das pessoas se preocuparem com várias dessas questões em graus diferentes, o que caracteriza a âncora é que o fato seja tão importante que passe a ser imprescindível. Com o conhecimento de sua inclinação profissional é possível perceber suas aptidões, preferências, objetivos e valores que caracterizam suas escolhas, como fatores que não renunciaria em sua carreira, e qual seria a única opção da qual o individuo não abriria mão quando obrigado a fazer uma escolha. Quando as ocupações não são compatíveis com a âncora de seu ocupante, esse indivíduo tende a apresentar um desempenho mediano. 0 modelo de âncora reforça a noção de que o autoconhecimento favorece a eficácia na tomada de decisão ocupacional e seu caráter processual (MARTINS, 2001).

Definidas pela área de maior importância para um indivíduo e os valores que ele prioriza, foram identificadas oito categorias de inclinações profissionais, conforme segue:

- Aptidão Técnica e Funcional (TF): o que move as pessoas dessa âncora é exercitar suas aptidões e continuar a desenvolvê-las ao máximo, buscam ser referência de especialista (SCHEIN, 1993). 
- Gerência geral (GG): as pessoas dessa âncora têm como objetivo subir os degraus hierárquicos da empresa até alcançar os cargos de maior responsabilidade (SCHEIN, 1996).

- Autonomia e Independência (Al): o que move as pessoas dessa âncora é o fato de não suportarem estar presos a normas, regras, métodos e expedientes de trabalho.

- Segurança e Estabilidade (SE): é identificada nas pessoas que priorizam a segurança financeira e estabilidade no vínculo empregatício ao longo de toda sua trajetória profissional (SCHEIN, 1993).

- Criatividade Empreendedora (CE): pessoas que se sentem motivadas para criar novos negócios próprios desenvolvendo novos produtos e serviços (SCHEIN, 1993).

- Dedicação a uma Causa (SD): são indivíduos que se sentem satisfeitos em contribuir para a melhoria da sociedade, em tornar o mundo um lugar melhor para viver (SCHEIN, 1996).

- Puro Desafio (PD): integra indivíduos competitivos que valorizam superar obstáculos e solucionar problemas aparentemente insolúveis (SCHEIN, 1993).

- Estilo de Vida (EV): é identificada em indivíduos que buscam equilibrar as esferas pessoais e profissionais (SCHEIN, 1993).

\subsection{GERAÇÃO Y}

Geração refere-se ao conjunto de indivíduos nascidos em uma mesma época, sendo que cada geração possui determinadas características, valores e princípios distintos uns dos outros. Começando na infância, as gerações formam como se fosse um ciclo e sempre devem adaptar-se para que possam conviver umas com as outras de forma harmoniosa (CARNEIRO, 2010).
Quando se fala em geração $Y$, deve-se em primeiro lugar entender o contexto histórico em que a mesma se situa, bem como entender o seu perfil. De acordo com Kupperschmidt (2000), as diferenças entre gerações em uma empresa, por exemplo, se não compreendidas, podem gerar tensão, confronto, insatisfação e diminuir a produtividade.

Os membros pertencentes à geração $Y$ são indivíduos que nasceram entre os anos de 1982 e 2000 (RUGIMBANA, 2007). A Geração Y faz parte do chamado ciclo idealista, porque se pode fazer uma correlação entre as suas características principais, o empreendedorismo, a independência e a honestidade. Alguns autores, como McCrindle (2002), afirmam que a condição social, política e econômica é um fator diferencial no comportamento das gerações. Cada geração possui diferentes características pessoais e estilo de vida em relação aos valores, família, educação, comunicação e finanças.

Os "Y's", como são geralmente chamados, não tem medo de arriscar e a buscam novos desafios, detestam monotonia, não costumam ficar muito tempo numa mesma organização, tem conhecimentos técnicos e capacitação profissional. Eles trabalham melhor em equipes e procuram empregos que ofereçam flexibilidade de horário, mobilidade e planos de carreira.

Conhecer a Geração Y com mais detalhes, poderá ajudar os gestores a trabalhar efetivamente para que haja uma maior produtividade e melhor aproveitamento de suas competências e potenciais, pois é a mais recente geração a entrar no mercado de trabalho.

\section{METODOLOGIA}

Para atingir os objetivos propostos neste artigo os autores optaram por escolher uma pesquisa do 
tipo descritiva e de natureza quantitativa. 0 trabatho integra a pesquisa bibliográfica e o estudo de campo, envolvendo o uso de questionários como o principal instrumento de coleta de dados.

A escolha dos sujeitos para a composição da amostra utilizou o critério de acessibilidade (VERGARA, 2007). Os participantes desse estudo foram 252 alunos do curso de Engenharia da Universidade Federal do $A B C$, na sua grande maioria pertencentes à geração $\mathrm{Y}$.

O questionário aplicado foi composto por duas partes, sendo que a primeira parte é referente ao perfil do entrevistado, formada por 10 perguntas. A segunda parte corresponde ao inventário das ancoras de carreira de Schein (1993), que consiste em um instrumento com 40 afirmativas. Fazendo uso de uma escala do tipo Likert (seis pontos), com significado de nunca verdadeiro (1) até mais verdadeiro (6), o respondente atribui uma classificação para caracterizar os oito tipos de ancoras de carreira predominantes.

O tratamento dos dados foi feito com auxilio do pacote estatístico SPSS (versão 18.0) e os resultados organizados em análise descritiva e análise inferencial. Primeiramente, foram calculadas as pontuações de cada âncora de carreira e identificada à âncora com pontuação superior para cada indivíduo. Para as análises inferenciais foram utilizados testes de Qui-quadrado, avaliando se havia associação das âncoras de carreira com o gênero, a idade e a formação anterior. O teste de Qui-quadrado foi utilizado por ser um teste não paramétrico que permitiu avaliar a associação entre duas variáveis categóricas (nominais ou ordinais) por meio de uma tabela de contingência.

\section{ANÁLISE DOS DADOS}

Nesse tópico são apresentados os dados obtidos, na forma de análise descritiva (da amostra e das ancoras de carreira) e inferencial.

\subsection{ANÁLISE DESCRITIVA DA AMOSTRA}

A Figura 1 mostra que a maioria dos entrevistados (92\%) tem entre 18 e 25 anos, ou seja, pertencentes à geração $\mathrm{Y}$.

Figura 1 - Análise descritiva da idade

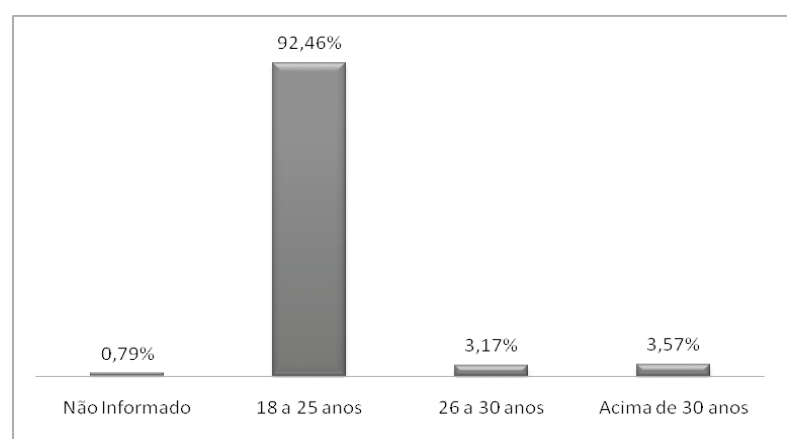

A Figura 2 apresenta o gênero dos entrevistados. A maioria são homens (59\%) e uma quantidade considerável de entrevistados não informou o gênero (17\%).

Figura 2 - Análise descritiva do gênero

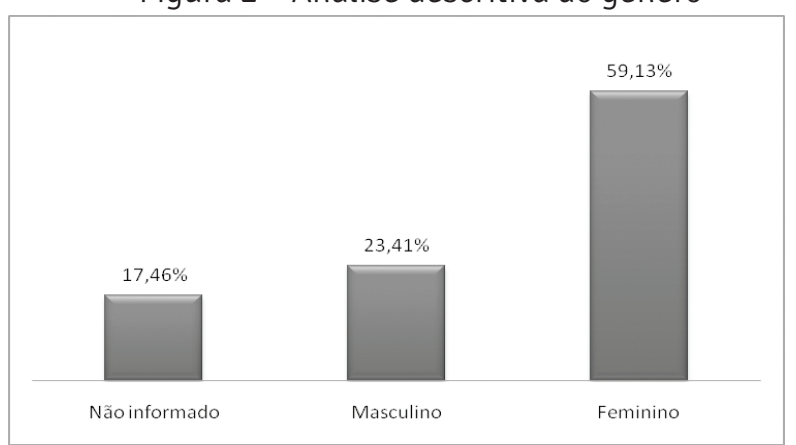


Nota-se na Figura 3 que a maioria dos entrevistados concluiu apenas o ensino médio ( $68 \%), 24 \%$ concluíram o ensino técnico de nível médio e $7 \%$ possuem outra graduação completa.

Figura 3 - Análise descritiva da formação anterior

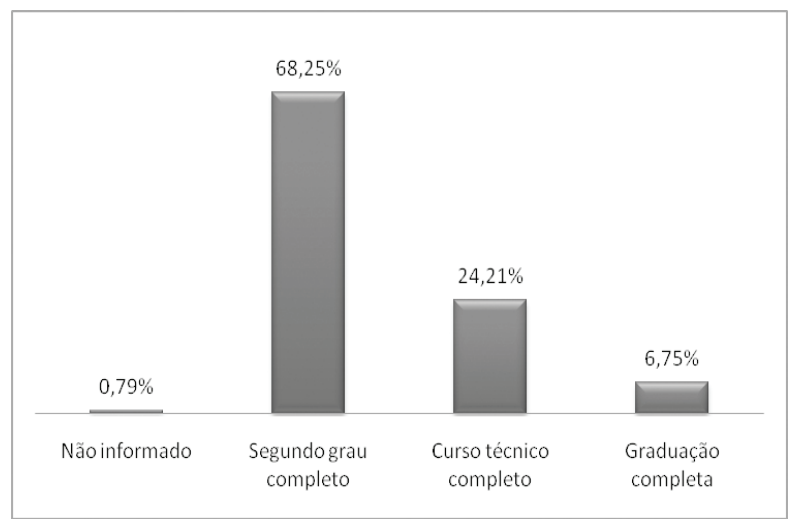

\subsection{ANÁLISE DESCRITIVA DAS ANCORAS DE CARREIRA}

A Figura 4 indica que 46 entrevistados (18\%) têm o Estilo de Vida como a principal âncora de carreira, para 16\% (40 entrevistados) a Segurança e Estabilidade é a âncora principal, a Gerência Geral é a âncora de 28 entrevistados (11\%), para 10\% dos entrevistados a Autonomia e Independência é a âncora principal. A âncora Puro Desafio representa 9\% dos entrevistados, já as ancoras Técnico-Funcional e Criatividade Empreendedora foram identificadas como principais por $7 \%$ dos entrevistados (17 cada) e a âncora com menor frequência é a de Serviço e Dedicação a Uma Causa, 13 entrevistados, representando $5 \%$. Os entrevistados que possuem duas âncoras principais representam 17\% (42 entrevistados).
Figura 4 - Análise descritiva das ancoras de carreira

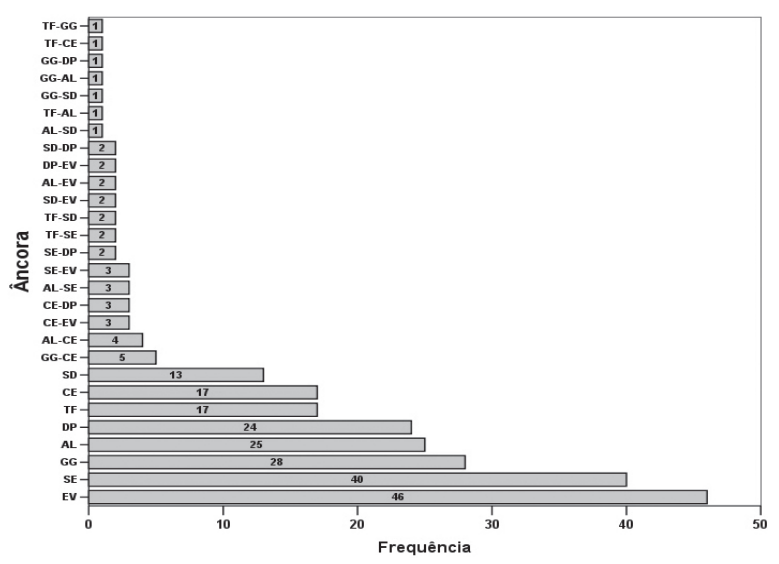

\section{DISCUSSÃO DOS DADOS}

O presente estudo utilizou-se da abordagem de ancoras de carreira de Schein (1993), visando identificar a relação entre os objetivos de vida e valores com a predisposição para se trilhar uma carreira.

Figura 5 - Análise descritiva das ancoras de carreira

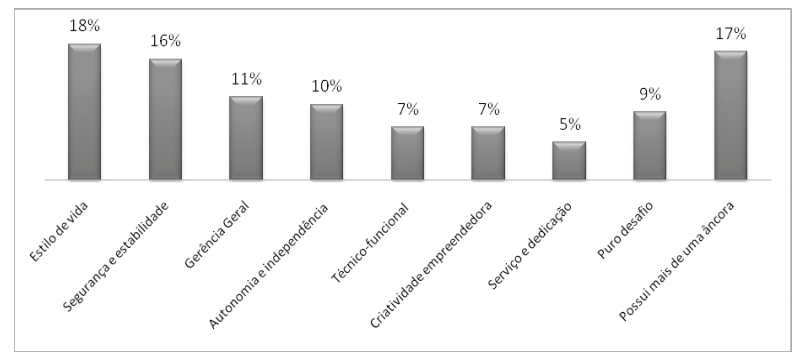

As principais âncoras encontradas com os alunos de graduação em Engenharia foram Estilo de Vida (18\%), Segurança e Estabilidade (16\%), pouco menos da metade dos entrevistados que possuem apenas uma âncora de carreira mostram uma maior busca pela Qualidade de Vida, mas associada à segurança. A instabilidade do mercado de trabalho tem estimulado a busca dos jovens por empresas que 
ofereçam estabilidade, ascensão e bons salários associados a uma melhor qualidade de vida. Isso exige dos jovens profissionais que adquiram habilidades de gerenciamento da própria carreira profissional.

Em terceiro lugar, Gerência Geral (11\%), é uma das competências de maior valorização no mundo empresarial e associada às tendências do mercado de trabalho, com a visão para solucionar problemas e tomar decisões em situações de incerteza e com falta de informação.

A âncora que apresenta menor frequência é Serviço e Dedicação a Uma Causa (5\%), confirmado pela noção proteana de carreira, na qual a carreira profissional de hoje pode assumir diferentes formas (MARTINS, 2001), não apresentando apenas uma causa exclusiva.

Os entrevistados que possuem duas âncoras principais representam $17 \%$. Esse elevado número se deve ao fato da pouca idade dos entrevistados, nos quais a falta de experiência profissional é um fator decisivo, pois a noção das ancoras torna-se mais óbvia e consistente com a acumulação da experiência no trabalho.

Santos e Abrahim (2008) analisaram a influência dos valores pessoais na determinação das âncoras de carreira de 42 universitários dos cursos de Administração e Contabilidade do Centro Universitário do Pará (CESUPA) e da Pontifícia Universidade Católica de São Paulo (PUC-SP) e observaram que apesar da aparente homogeneidade do grupo não houve a predominância de uma âncora isolada na primeira posição.

A Figura 6 mostra os resultados obtidos com os alunos de Engenharia e de Administração. No estudo realizado com os alunos de Engenharia, existe grande predominância das âncoras Estilo de Vida e Segurança e Estabilidade. Na pesquisa realizada com alunos da Administração observou- -se a predominância das âncoras Puro Desafio e Técnico-Funcional, e a ausência de indivíduos que apresentem a âncora Segurança e Estabilidade, que é a segunda âncora com maior frequência entre os alunos de Engenharia. As diferenças encontradas podem estar relacionadas aos diferentes tamanhos das amostras analisadas.

Figura 6 - Âncoras de carreira: estudo comparativo entre alunos de Engenharia e Administração

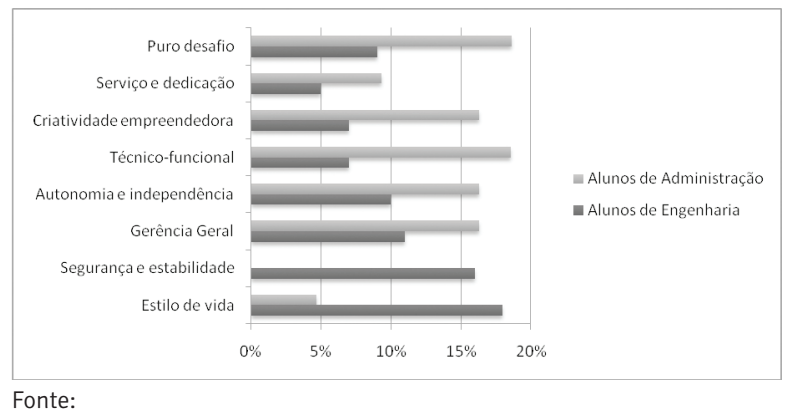

\section{CONCLUSÕES E CONSIDERAÇÕES FINAIS}

A combinação das maiores âncoras Estilo de Vida e Segurança e Estabilidade mostram a busca pela estabilidade da carreira tradicional e pelo equilíbrio das esferas pessoais e profissionais, portanto procura-se integrar as necessidades do trabalho com as necessidades individuais e familiares, influenciando diretamente na trajetória profissional.

A amostra estudada é composta de indivíduos jovens que fazem parte da geração $Y$, tendo como características principais a busca de novos desafios, apesar de valorizarem a segurança e a estabilidade no emprego. Com relação à análise inferencial não foi identificada associação entre as âncoras de carreira e as variáveis individuais denominadas idade, sexo e formação escolar anterior, pois apresentaram nível de significância muito pequeno. 
Tradicionalmente, poucos indivíduos mudavam de emprego ou de carreira durante o curso de sua vida, mas, atualmente, isso ocorre com muita frequência. No entanto a maior parte dos novos profissionais não está preparada para administrar sua própria carreira, sendo esta uma das atuais necessidades, pois se transfere para o trabalhador a responsabilidade de administrar as transições em sua carreira e em sua vida.

Como proposta de novas e futuras investigações, recomenda-se ampliar e diversificar o espaço amostral para a temática de gestão e âncoras de carreira, visando preencher a lacuna acadêmica ainda existente no assunto e contribuir de forma mais relevante com os gestores de Recursos Humanos.

\section{REFERÊNCIAS}

ARTHUR, M. B, KHAPOVA, S. N., \& WILDEROM, C. P. M. Career Success in a Boundary less Career World. Journal of Organizational Behavior. n.26, 2005, p.177-202.

CARNEIRO, N. A. Turismo de Negócios e a Geração Y no Cenário de Eventos Empresariais. Tese de Mestrado em Turismo, Universidade Anhembi Morumbi, São Paulo, 2010. Disponível em: <http:// portal.anhembi.br/publique/cgi/cgilua.exe/sys/ start.htm?infoid=6696\&sid=140>. Acesso em:

CHANLAT, J. F. Quais carreiras e para qual sociedade? Revista de Administração de Empresa, São Paulo, v.35, n.6, nov./dez. 1995, p.67-75.

DUCCI, M. A. El enfoque de competência laboral en la perspectiva internacional. In Oficina Internacional del Trabajo. Formación baseada en competencia laboral: situación actual y perspectivas. Genebra: OIT, 1996.

DUTRA, J.S. A Gestão de Carreira. in: FLEURY, M. T.L. (Org.). As Pessoas na Organização. 8ed. São Paulo: Gente, 2002.
HALL, D.T, \& MIRVIS, P.H. Careers as Lifelong Learning, In: The Changing Nature of Word. San Francisco: Jossey Bass, 1995.

HALL, D. T. The career is dead, long live the career: A relational approach to careers. San Francisco, CA: Jossey-Bass. 1996.

KUPPERSCHMIDT, B. R. Multigeneration Employees: strategies for effective management. The Health Care Manager, 19(1, 2000), p.65-76.

LUZ, T. R. Telemar-Minas: Competências que marcam a diferença. Tese (Doutorado em Administração), Universidade Federal de Minas Gerais, Belo Horizonte, 2001.

MARTINS, H. T. Gestão de carreiras na era do conhecimento: abordagem conceitual \& resultados de pesquisa. Rio de Janeiro: Qualitymark, 2001.

MCCRINDLE, M. Understanding Generation Y. Australia: The Australian Leadership Foundation, 2002.

MCDANIELS C., \& GYSBERS N. C. Counseling for Career Development: Theories, Resources and Practice. San Francisco, CA: Jossey Bass,1992.

ROBBINS, S.P. Comportamento Organizacional. Rio de Janeiro: Livros Técnicos e científicos, 1998.

ROBERT, P. Le petit Robert. Montréal: les dictionnaires Robert, 1989.

RUGIMBANA, R. Generation Y: How cultural values can be used to predict their choice of electronic financial services. Journal of Financial Services Marketing, v.11, n.4, 2007, p.301-313(13).

SANTOS, N.M.B.F., \& ABRAHIM, G.S. A Influência dos Valores Pessoais na Determinação das Ancoras de Carreira. In: Encontro da Associação Nacional de Pós-Graduação em Administração, 2008. 
SCHEIN, E. H. Career Anchors: discovering your real values. San Diego: Pfeiffer \& Company, 1993.

SCHEIN, E. H. Identidade Profissional: como ajustar suas inclinações a suas opções de trabalho. São Paulo: Nobel, 1996.

Recebido em: 22 de Maio de 2014 Avaliado em:28 de Maio de 2014 Aceito em: 7 de Julho de 2014
SENNETT, R. A Corrosão do Caráter: as conseqüências pessoais do trabalho no novo capitalismo. 11.ed. Rio de Janeiro: Record, 2006.

VERGARA, S. C. Projetos e Relatórios de Pesquisa em Administração. 9.ed. São Paulo: Atlas, 2007.

ZARIFIAN, P. Objetivo competência: por uma nova lógica. São Paulo: Atlas, 2001.

1. Mestrando em Engenharia Elétrica - Universidade Federal do ABC UFABC. E-mail: igor.munhoz@ufabc.edu.br

2. Professora Doutora da Pontifícia Universidade Católica de São Paulo - PUC-SP. E-mail: admneusa@pucsp.br

3. Pós-Doutorando - Pontifícia Universidade Católica de São Paulo PUC-SP. E-mail: jorgeknupp@gmail.com

4. Professor Doutor da Pontifícia Universidade Católica de São Paulo PUC-SP - setrob@pucsp.br

5. Doutoranda em Biossistemas - Universidade Federal do ABC UFABC. E-mail: alessandra-cris@uol.com.br

6. Mestrando em Administração - Pontifícia Universidade Católica de São Paulo - PUC-SP. E-mail: luishenriquel@globo.com 